\title{
Evaluation of clinico-radiological factors affecting morbidity and mortality in peptic ulcer perforation surgery
}

\author{
Mustafa Yeni' ${ }^{1}$, Murat Kartal$^{2} \oplus$, Tolga Kalayci ${ }^{3} \odot$ \\ Department of General Surgery, Erzurum Regional Training and Research Hospital, Erzurum, Turkey
}

\begin{abstract}
Objectives: Peptic ulcer perforation (PUP) remains a surgical emergency with high early period morbidity and mortality. In this study, it was aimed to evaluate clinico-radiological factors affecting morbidity and mortality in peptic ulcer perforation surgery.

Methods: Patients who were operated for PUP at Erzurum Regional Training and Research Hospital General Surgery Clinic, Erzurum, Turkey between 2010 and 2020 were selected retrospectively. The patients' clinical and radiological parameters were retrieved from their medical records. Patients who developed complications in the 30 days after surgery were considered the morbidity-positive group, and the patients who developed mortality in the 30 days after surgery were considered the mortality-positive group. The relationship between investigated factors and morbidity and mortality was investigated with suitable statistical tests. A $p$ value $<$ 0.05 was considered statistically significant.
\end{abstract}

Results: The study included 81 patients and, 74 (91.4\%) patients were males. Complications were observed in $15(18.5 \%)$ patients and mortality was seen in $3(3.7 \%)$ patients in the first 30 days postoperatively. Preoperative comorbidity, low systolic blood pressure, high Boey score had negative effect on both morbidity and mortality. In addition, lower amylase levels played a protective role in both morbidity $(p=0.011)$ and mortality $(p=0.018)$. Mortality increased significantly with increasing age. However, no radiological factor affected either morbidity or mortality.

Conclusions: Both morbidity and mortality increased in cases with poor clinical condition at the time of diagnosis. In addition, the mortality rate was higher in patients with comorbidities and postoperative complications.

Keywords: Amylase, Boey score, comorbidity, morbidity, mortality, peptic ulcer perforation

$\mathbf{P}$ eptic ulcer perforation (PUP) is one of the most important complications of peptic ulcer disease (PUD) [1]. Although the incidence of PUD decreased during the last few decades due to the successful treatment of Helicobacter pylori, the decrease in perforation cases was not as desired [2]. Perforation accounts for most deaths associated with PUD [3, 4]. PPU remains a surgical emergency, with high early period mortality of $10-30 \%$ and early period morbidity of $21-$ $43 \%[4,5]$.

Surgical repair with or without omentum is the most common surgical technique in PUP surgery. While surgical repair is most commonly performed with open surgery, laparoscopy are preferred in appropriate cases [6]. The laparoscopic treatment of PUP has been shown to be applicable and safe, but its im- 
plementation into routine clinical practice has been slow [5]. A Denmark study reported that only $6 \%$ of patients with PPU were treated with laparoscopic surgery [7].

The aim of this study is to evaluate clinico-radiological factors affecting morbidity and mortality in PUP surgery.

\section{METHODS}

Patients who were operated for PUP at Erzurum Regional Education and Research Hospital General Surgery Clinic, Erzurum, Turkey, between 2010 and 2020 were selected for the study retrospectively. Age and gender of the patients, preoperative comorbidity, systolic blood pressure (above or below $100 \mathrm{~mm} \mathrm{Hg}$ ), time from pain to hospital admission (longer or shorter than 24 hours) were evaluated. Since smoking is an important parameter in perforation etiology, the smoking of the patients was also evaluated. Boey scores of all patients were calculated. The components of the Boey score are as follows: concomitant medical illness, preoperative shock, perforation time greater than 24 hours. Each factor scores 1 point if positive. The total Boey score is calculated based on the individual scores of the parameters.

Preoperative laboratory parameters and imaging tools were also investigated. In hematological analysis, white blood cell (WBC) and platelet counts, hemoglobin values, leukocyte and lymphocyte counts were searched. In addition, amylase and lactate dehydrogenase (LDH) levels were investigated in biochemical analysis. Presence of free air both X-Ray radiograph and computed tomography $(\mathrm{CT})$ scan were investigated. Also, on CT scan, presence of intra-abdominal fluid was searched.

Surgery type, perforation location, postoperative complications, hospital stay, and mortality were also evaluated. After collecting the evaluated parameters, the relationship between the parameters and morbidity and mortality was analyzed.

Ethics committee approval was received from Non-invasive Clinical Research Ethics Committee of Erzurum Regional Education and Research Hospital, Erzurum, Turkey (Decision No: 2021/05-84).

\section{Statistical Analysis}

Statistical evaluation was made with SPSS v22.0 (IBM, Armonk, NY, USA). The normality distribution of quantitative variables were checked with ShapiroWilk test. The Mann-Whitney U test was used according to the results of the Shapiro-Wilk test. In addition, Chi-square test, and Likelihood ratio test were used to compare qualitative variables. A p value below 0.05 was considered statistically significant.

\section{RESULTS}

Between 2010 and 2020, 94 patients were operated on for PUP in Erzurum Regional Training and Research Hospital General Surgery Clinic, Erzurum, Turkey. Thirteen patients were excluded from the study because all data of these patients were not accessible. Thus, 81 patients were included in the study. After collecting the evaluated parameters, the effect of the collected parameters on morbidity and mortality was investigated. Complications were observed in 15 (18.5\%) patients and mortality was seen in $3(3.7 \%)$ patients in the first 30 days postoperatively. Patients were divided into groups according to morbidity and mortality.

$74(91.4 \%)$ patients were males and $7(8.6 \%)$ were females, and male to female ratio was 10.57 . The mean age of all patients was 44.81 years (range: 18 -

\section{Table 1. Comorbid diseases of the patients}

\begin{tabular}{lc}
\hline Comorbidity & n (\%) \\
\hline Hypertension & $10(62.5)$ \\
Chronic obstructive pulmonary disease (COPD) & $3(18.75)$ \\
Hypertension with COPD & $2(12.5)$ \\
Hypertension with diabetes mellitus & $1(6.25)$ \\
Total & $16(100)$ \\
\hline
\end{tabular}


Table 2. Comparison of clinical parameters according to morbidity

\begin{tabular}{|c|c|c|c|}
\hline Preoperative factors & $\begin{array}{c}\text { Morbidity positive } \\
\qquad \mathrm{n}=15\end{array}$ & $\begin{array}{c}\text { Morbidity negative } \\
n=66\end{array}$ & $p$ value \\
\hline Age (years) (mean) & 46.27 & 39.80 & $0.337^{*}$ \\
\hline Gender & & & $0.114^{* *}$ \\
\hline Female & $3(42.9 \%)$ & $4(57.1 \%)$ & \\
\hline Male & $12(16.2 \%)$ & $62(83.8 \%)$ & \\
\hline Comorbid disease & & & $0.001 * *$ \\
\hline Yes & $8(50 \%)$ & $8(50 \%)$ & \\
\hline No & $7(10.8 \%)$ & $58(89.2 \%)$ & \\
\hline Preoperative systolic blood pressure & & & $0.001 * *$ \\
\hline$<100 \mathrm{mmHg}$ & $7(58.3 \%)$ & $5(41.7 \%)$ & \\
\hline$\geq 100 \mathrm{mmHg}$ & $8(11.6 \%)$ & $61(88.4 \%)$ & \\
\hline Time from pain to admission & & & $0.932 * *$ \\
\hline$\geq 24$ hours & $8(18.2 \%)$ & $36(81.8 \%)$ & \\
\hline$<24$ hours & $7(18.9 \%)$ & $30(81.1 \%)$ & \\
\hline Boey score & & & $0.004 * * *$ \\
\hline 0 & $5(15.2 \%)$ & $28(84.8 \%)$ & \\
\hline 1 & $2(6.3 \%)$ & $30(93.8 \%)$ & \\
\hline 2 & $4(40 \%)$ & $6(60 \%)$ & \\
\hline 3 & $4(66.7 \%)$ & $2(33.3 \%)$ & \\
\hline Cigarette usage & & & $0.701^{* *}$ \\
\hline Yes & $9(20 \%)$ & $36(80 \%)$ & \\
\hline No & $6(16.7 \%)$ & $30(83.3 \%)$ & \\
\hline \multicolumn{4}{|l|}{ Laboratory test results (mean) } \\
\hline WBC $\left(10^{3} / \mathrm{mm}^{3}\right)$ & 15.27 & 13.02 & $0.484 *$ \\
\hline Neutrophil $\left(10^{3} / \mathrm{mm}^{3}\right)$ & 10.87 & 10.46 & $0.670^{*}$ \\
\hline Lymphocyte $\left(10^{3} / \mathrm{mm}^{3}\right)$ & 3.44 & 1.83 & $0.555^{*}$ \\
\hline Platelet $\left(10^{3} / \mathrm{mm}^{3}\right)$ & 292.53 & 274.23 & $0.870^{*}$ \\
\hline Amilase (U/L) & 58.07 & 95.70 & $0.011 *$ \\
\hline $\mathrm{LDH}(\mathrm{U} / \mathrm{L})$ & 261.20 & 247.67 & $0.359^{*}$ \\
\hline Free air on X-Ray & & & $0.983 * *$ \\
\hline Yes & $8(18.6 \%)$ & $35(81.4 \%)$ & \\
\hline No & $7(18.4 \%)$ & $31(81.6 \%)$ & \\
\hline Free air on CT scan & & & $0.113 * *$ \\
\hline Yes & $15(22.1 \%)$ & $53(77.9 \%)$ & \\
\hline No & $0(0 \%)$ & $13(100 \%)$ & \\
\hline Fluid at CT scan & & & $0.742 * *$ \\
\hline Yes & $10(19.6 \%)$ & $41(80.4 \%)$ & \\
\hline No & $5(16.7 \%)$ & $25(83.3 \%)$ & \\
\hline \multicolumn{4}{|l|}{ Operative factors } \\
\hline Type or surgery & & & $0.464 * *$ \\
\hline Open & $14(17.9 \%)$ & $61(82.1 \%)$ & \\
\hline Laparoscopic & $1(33.3 \%)$ & $2(66.7 \%)$ & \\
\hline Perforation localization & & & $0.001 * * *$ \\
\hline Pre-pyloric area & $9(39.1 \%)$ & $14(60.9 \%)$ & \\
\hline Juxta-pyloric area & $4(23.5 \%)$ & $13(76.5 \%)$ & \\
\hline Post-pyloric area & $2(4.9 \%)$ & $39(95.1 \%)$ & \\
\hline
\end{tabular}

* Mann-Whitney U Test, **Chi-square test, ***Likelihood ratio test. $\mathrm{WBC}=$ White Blood Cell, LDH $=$ Lactate

Dehydrogenase, $\mathrm{CT}=$ Computed Tomography 
Table 3. Comparison of clinical parameters according to mortality

\begin{tabular}{|c|c|c|c|}
\hline & $\begin{array}{l}\text { Mortality positive } \\
\qquad \mathbf{n}=\mathbf{3}\end{array}$ & $\begin{array}{c}\text { Mortality negative } \\
\quad \mathbf{n}=\mathbf{7 8}\end{array}$ & $p$ value \\
\hline \multicolumn{4}{|l|}{ Preoperative factors } \\
\hline Age (years) (mean) & 78.17 & 39.57 & $<0.001 *$ \\
\hline Gender & & & $0.240^{* *}$ \\
\hline Female & $1(14.3 \%)$ & $6(85.7 \%)$ & \\
\hline Male & $2(2.7 \%)$ & $72(97.3 \%)$ & \\
\hline Comorbid disease & & & $0.007 * *$ \\
\hline Yes & $3(18.8 \%)$ & $13(81.2 \%)$ & \\
\hline No & $0(0 \%)$ & $65(100 \%)$ & \\
\hline Preoperative systolic blood pressure & & & $0.003^{* * *}$ \\
\hline$<100 \mathrm{mmHg}$ & $3(25 \%)$ & $9(75 \%)$ & \\
\hline$\geq 100 \mathrm{mmHg}$ & $0(0 \%)$ & $69(100 \%)$ & \\
\hline Time from pain to admission & & & $0.246^{* *}$ \\
\hline$\geq 24$ hours & $3(6.8 \%)$ & $41(93.2 \%)$ & \\
\hline$<24$ hours & $0(0 \%)$ & $37(100 \%)$ & \\
\hline Boey score & & & $<0.001 * * *$ \\
\hline 0 & $0(0 \%)$ & $33(100 \%)$ & \\
\hline 1 & $0(0 \%)$ & $32(100 \%)$ & \\
\hline 2 & $0(0 \%)$ & $10(100 \%)$ & \\
\hline 3 & $3(50 \%)$ & $3(50 \%)$ & \\
\hline Cigarette usage & & & $0.084^{* *}$ \\
\hline Yes & $0(0 \%)$ & $45(100 \%)$ & \\
\hline No & $3(8.3 \%)$ & $33(91.7 \%)$ & \\
\hline \multicolumn{4}{|l|}{ Laboratory test results (mean) } \\
\hline $\operatorname{WBC}\left(10^{3} / \mathrm{mm}^{3}\right)$ & 17.38 & 13.33 & $0.934^{*}$ \\
\hline Neutrophil $\left(10^{3} / \mathrm{mm}^{3}\right)$ & 13.58 & 10.42 & $0.480^{*}$ \\
\hline Lymphocyte $\left(10^{3} / \mathrm{mm}^{3}\right)$ & 3.38 & 2.08 & $0.953^{*}$ \\
\hline Platelet $\left(10^{3} / \mathrm{mm}^{3}\right)$ & 272.67 & 277.81 & $0.543^{*}$ \\
\hline Amilase (U/L) & 36.00 & 90.76 & $0.018 *$ \\
\hline $\mathrm{LDH}(\mathrm{U} / \mathrm{L})$ & 360.33 & 245.94 & $0.053^{*}$ \\
\hline Free air on X-Ray radiograph & & & $0.598 * *$ \\
\hline Yes & $1(2.3 \%)$ & $42(97.7 \%)$ & \\
\hline No & $2(5.3 \%)$ & $36(94.7 \%)$ & \\
\hline Free air on CT scan & & & $>0.999 * *$ \\
\hline Yes & $3(4.4 \%)$ & $65(95.6 \%)$ & \\
\hline No & $0(0 \%)$ & $13(100 \%)$ & \\
\hline Fluid at CT scan & & & $0.292 * *$ \\
\hline Yes & $3(5.9 \%)$ & $48(94.1 \%)$ & \\
\hline No & $0(0 \%)$ & $30(100 \%)$ & \\
\hline \multicolumn{4}{|l|}{ Operative Factors } \\
\hline Type or surgery & & & $>0.999 * *$ \\
\hline Open & $3(3.8 \%)$ & $75(96.2 \%)$ & \\
\hline Laparoscopic & $0(0 \%)$ & $3(100 \%)$ & \\
\hline Perforation localization & & & $0.258 * * *$ \\
\hline Pre-pyloric area & $1(4.3 \%)$ & $22(95.7 \%)$ & \\
\hline Juxta-pyloric area & $2(11.8 \%)$ & $15(88.2 \%)$ & \\
\hline Post-pyloric area & $0(0 \%)$ & $41(100 \%)$ & \\
\hline Morbidity & & & $0.005 * *$ \\
\hline Yes & $3(20 \%)$ & $12(80 \%)$ & \\
\hline No & $0(0 \%)$ & $66(100 \%)$ & \\
\hline
\end{tabular}

*Mann-Whitney U Test, **Chi-square test, ***Likelihood ratio test. WBC $=$ White Blood Cell, LDH $=$ Lactate

Dehydrogenase, $\mathrm{CT}=$ Computed Tomography 
84 years). While no relationship was found between age and morbidity, mortality increased with increasing age $(p<0.001)$. Sixteen $(19.8 \%)$ patients had at least one comorbid disease. Comorbid diseases of the patients are shown in Table 1.

In $12(14.9 \%)$ patients, preoperative systolic blood pressure was under $100 \mathrm{~mm} / \mathrm{Hg}$. In 44 (54.3\%) patients, time from pain to hospital admission was longer than 24 hours. The most common Boey score of the study was Boey $0(\mathrm{n}=33,40.7 \%)$. The percentages for Boey 1, 2, and 3 were $39.5 \%, 12.3 \%$ and $7.4 \%$, respectively. In addition, cigarette consumption was present in $55.6 \%(\mathrm{n}=45)$ of all patients. There was a correlation between the presence of comorbid disease, low systolic blood pressure, high Boey score, and both morbidity and mortality. While the morbidity rate was $66.7 \%$ in patients with Boey 3 score, the mortality rate was $50 \%$. As the Boey score increased, the possibility of both morbidity and mortality increased.

On laboratory, 58 (71.6\%) patients had leukocytosis, and 57 (70.4\%) patients had neutrophilia. According to laboratory evaluation, only amylase levels played a role in both morbidity $(p=0.011)$ and mortality $(p=0.018)$. Both morbidity and mortality were inversely proportional to the rising amylase level.

On imaging tools examination, subdiaphragmatic free air on right side was observed in 43 (53\%) patients on plain radiography. Plain radiography was not taken in $20(24.7 \%)$ patients under emergency conditions. However, free air was also present on tomography in all patients with free air on plain radiography. On CT scan, 68 (84\%) patients had intra-abdominal free air, $51(63 \%)$ patients had free fluid in the abdomen. On the other hand, there was no pathological finding on CT scan in $13(16 \%)$ patients. The presence of free air and free fluid in imaging methods affected neither morbidity nor mortality.

Open surgery was preferred surgery type in 78 $(96.3 \%)$ patients. The remaining operations were performed via laparoscopy. Graham's omental patch closure was performed in all patients to close the perforation defect. Most of the surgery notes could not be evaluated because there was no information about the perforation diameter in operation notes. In addition, the most common area of perforation was the post-pyloric area $(\mathrm{n}=41,50.6 \%)$. Other perforation areas and percentages were as follows: $28.4 \%$ at prepyloric area, and $21 \%$ at juxta-pyloric area. Morbidity rate was higher in pre-pyloric area perforations with $39.1 \%(p=0.001)$. In the patients with morbidity, mortality was also higher $(p=0.005)$. Evaluation of morbidity and mortality according to clinical and radiological parameters is shown in Table 2 and Table 3.

The morbidity rate of the study was $18.5 \%$. The most common postoperative complication was surgical site infection with $46.7 \%$. The incidence of pulmonary complications was $33.3 \%$. Postoperative complications and treatment of these complications are shown in Table 4 . The mean length of hospital stay was 8.23 days (3-16 days). Mortalite rate of our study was $3.7 \%(n=3)$. All patients died because of multi organ failure and sepsis.

\section{DISCUSSION}

This study's results demonstrate that morbidity of PUP surgery was higher at the patients with preoperative comorbidity, shock, higher Boey score, and perforation localized pre-pyloric area. In addition, mortality of PUP surgery was higher at the patients with advanced age, preoperative comorbidity, shock,

Table 4. Postoperative complications and treatment of these complications

\begin{tabular}{llc}
\hline Postoperative complications & Treatment & n (\%) \\
\hline Surgical site infection & Local drainage with daily cleaning & $7(46.7)$ \\
$\begin{array}{l}\text { Multi organ failure and sepsis (all } \\
\text { these patients died) }\end{array}$ & $\begin{array}{l}\text { Combine antibiotherapy with fluid support } \\
\text { therapy }\end{array}$ & $3(20)$ \\
Atelectasis & Breathing exercises & $2(13.3)$ \\
Pleural effusion & Drainage without chest tube & $2(13.3)$ \\
& Drainage with chest tube & $1(6.7)$ \\
Total & & $15(100)$ \\
\hline
\end{tabular}


higher Boey score, and morbidity. However, lower amylase level had a protective effect on both morbidity and mortality.

In literature, PUP cases are more likely to be seen in male gender and are mostly seen in the 4th and 5th decades [8-11]. In the present study, the male/female ratio was 10.57 , which was consistent with the literature. On the other hand, the mean age of all patients was 44.81 years, which was consistent with the literature too.

There was no consensus on a specific gender and age limit that determined morbidity and mortality. In the study of Kim et al. [12], age above sixty and female gender were affected morbidity. However, Kocer et al. [10] showed that PUP cases were mostly seen in the male gender (88.8 vs. 11.2). Y1ldirım et al. [13] showed that age over 50 years increased both morbidity and mortality. In this study, gender did not affect both morbidity and mortality. However, advanced age only affected mortality.

Since smoking is more preferred in male gender and the incidence of smoking increases, perforation rates are higher in male gender $[14,15]$. The smoking prevalence of present study was $55.6 \%$ and was not correlated with higher morbidity and mortality. On the contrary, Kocer et al. [10] showed that smoking increased mortality but did not affect morbidity. Contrary to the literature, smoking did not affect both morbidity and mortality in the present study.

As in the literature, the presence of preoperative shock increases mortality like our study [10, 16, 17]. Tas et al. [18] did not identified correlation between shock and morbidity. In contrast, preoperative shock increased morbidity in the present study. Comorbidities, higher ASA (American Society of Anesthesiologist) score and from pain to hospital application are also important factors for morbidity and mortality [5, 9-11, 19]. However, in the recent study, no relationship was found between the time of onset of pain and both morbidity and mortality. But comorbid diseases played an important role in increasing morbidity and mortality. As a limitation of our study, ASA scores of the patients could not be accessed and evaluated.

Boey score is a useful tool for assessing the prognosis of operated cases due to PUP and helps in the evaluation of both morbidity and mortality [14]. While mortality is between $30-60 \%$ in patients with a Boey score of 2, in Boey score 3 cases, mortality reaches
$100 \%$. In our study, all deaths had a Boey score of 3.

Laboratory parameters can also help to predict PUP. Yamamoto et al. [20] showed that while serum WBC count and platelet count were higher in perforation group, hemoglobin level, total protein and albumin levels, AST and ALT levels were higher in non-perforation group. Amylase levels were higher in patients with morbidity and mortality in follow-up and higher amylase levels were correlated with duration of perforation, size of perforation, and amount of fluid determined intraoperatively [21]. However, in contrast to the literature in the present study, both morbidity and mortality were high in patients with low serum amylase levels.

In plain radiography, $47.2-80 \%$ of patients with perforation had sub-diaphragmatic free air on the right side $[10,22]$. On the other hand, CT scan has a high diagnostic accuracy of $98 \%$ in the diagnosis of PUP [12]. In $35 \%$ of gastroduodenal perforations, there is no direct or indirect finding in imaging methods [23]. In this study, while subdiaphragmatic free air on right side was observed in $53 \%$ of the patients on plain radiography, free air was also present on tomography in $84 \%$ of all patients. On the other hand, there was no pathological finding on CT scan in $16 \%$ of the patients.

In the studies of Tas et al. [18] and Y1ldirim et al. [13] free air on plain radiograph and perforation localization were not affected both morbidity and mortality. There was no relationship between the presence of free air in imaging tools and morbidity and mortality.

Type of surgery, perforation diameter wider than $5 \mathrm{~mm}$ and performing definitive procedures for treatment were also factors on morbidity and mortality [10, 18]. However, Yildirım et al. [13] showed that the perforation diameter larger than $5 \mathrm{~mm}$ and the amount of fluid detected intraoperatively did not affect morbidity, but did affect mortality. Additionally, one study showed that even intra-abdominal fluid above $200 \mathrm{cc}$ affected morbidity [24]. Effects on morbidity and mortality could not be evaluated since most of the surgery notes did not have any information about the perforation diameter and intra-abdominal fluid in our study. In addition, surgical procedures could not be compared since all patients were operated with primary closure with omental patch. But in the study of Y1ldırım et al. [13], treatment with only primary suture increased both morbidity and mortality. 
The post-operative morbidity rate in PUP surgery ranges between $21-42 \%$ [10, 25]. Pulmonary and surgery site infections are often the main cause of postoperative complications [11]. The morbidity rate in the presented study was $18.5 \%$, which was partially lower than the literature.

In literature, length of stay after surgery in patients with PUP ranges between 7-12.5 days [9, 26]. In line with the literature, the average length of hospital stay in this study was 8.23 days.

\section{Limitations}

There were some limitations in this study. This study was a retrospective study, and the patients were excluded because the data of 13 patients were not available. The relationship between ASA score, perforation diameter and amount of intra-abdominal fluid and early outcomes could not be evaluated due to the lack of information. In addition, the small number of patients included in the study is an important limitation.

\section{CONCLUSION}

Peptic ulcer perforation (PUP) is a serious disease that every surgeon may encounter. PUP remains a surgical emergency with high early period morbidity and mortality. From our study's results, both morbidity and mortality increased in cases with poor clinical condition at the time of diagnosis. In addition, the mortality rate was higher in patients with comorbidities and postoperative complications. Diagnosis and necessary surgical treatment should be done as early as possible to prevent morbidity and mortality.

\section{Authors' Contribution}

Study Conception: MY, TK; Study Design: MY, MK; Supervision: MY; Funding: MK, TK; Materials: MY, MK; Data Collection and/or Processing: MY, TK; Statistical Analysis and/or Data Interpretation: MY, TK; Literature Review: MY, MK, TK; Manuscript Preparation: MY, TK and Critical Review: MY.

\section{Conflict of interest}

The authors disclosed no conflict of interest during the preparation or publication of this manuscript.

\section{Financing}

The authors disclosed that they did not receive any grant during conduction or writing of this study.

\section{REFERENCES}

1. Eisner F, Hermann D, Bajaeifer K, Glatzle J, Königsrainer A, Küper MA. Gastric ulcer complications after the introduction of proton pump inhibitors into clinical routine: 20-year experience. Visc Med 2017;33:221-6.

2. Dutta AK, Chacko A, Balekuduru A, Sahu MK, Gangadharan SK. Time trends in epidemiology of peptic ulcer disease in India over two decades. Indian J Gastroenterol 2012;31:111-5.

3. Tarasconi A, Coccolini F, Biffl WL, Tomasoni M, Ansaloni L, Picetti E, et al. Perforated and bleeding peptic ulcer: WSES guidelines. World J Emerg Surg 2020;15:1-24.

4. Svanes C. Trends in perforated peptic ulcer: incidence, etiology, treatment, and prognosis. World J Surg 2000;24:277-83.

5. Thorsen K, Glomsaker TB, von Meer A, Søreide K, Søreide JA. Trends in diagnosis and surgical management of patients with perforated peptic ulcer. J Gastrointest Surg 2011;15:1329-35.

6. Byrne BE, Bassett M, Rogers CA, Anderson ID, Beckingham I, Blazeby JM. Short-term outcomes after emergency surgery for complicated peptic ulcer disease from the UK National Emergency Laparotomy Audit: a cohort study. BMJ Open 2018;8:e23721.

7. Sommer T, Elbroend H, Friis-Andersen H. Laparoscopic repair of perforated ulcer in Western Denmark--a retrospective study. Scand J Surg 2010;99:119-21.

8. Özkan E, Dulundu E, Özel Y, Yıldız MK, Yardımcı S, Topaloğlu. [Size determines morbidity, older age and ASA score determines mortality in peptic ulcus perforation]. Haydarpaşa Numune Eğitim ve Araştırma Hastanesi Tip Dergisi 2008;48:222-8. [Article in Turkish]

9. Kamani F, Moghimi M, Marashi SA, Peyrovi H, Sheikhvatan M. Perforated peptic ulcer disease: mid-term outcome among Iranian population. Turk J Gastroenterol 2010;21:125-8.

10. Kocer B, Surmeli S, Solak C, Unal B, Bozkurt B, Yildirim $\mathrm{O}$, et al. Factors affecting mortality and morbidity in patients with peptic ulcer perforation. J Gastroenterol Hepatol 2007;22:56570.

11. Bas G, Eryilmaz R, Okan I, Sahin M. Risk factors of morbidity and mortality in patients with perforated peptic ulcer. Acta Chir Belg 2008;108:424-7.

12. Kim HC, Kim SW, Park SJ. Gastrointestinal tract perforation: evaluation of MDCT according to perforation site and elapsed time. Eur Radiol 2014;24:1386-93

13. Yıldırım M, Engin Ö, İlhan E, Coşkun A. Risk factors and Mannheim Peritonitis Index for the prediction of morbidity and mortality in patients with peptic ulcer perforation. Nobel Med 2009;5:74-81.

14. Agarwal A, Jain S, Meena L, Jain SA, Agarwal L. Validation of Boey's score in predicting morbidity and mortality in peptic perforation peritonitis in Northwestern India. Trop Gastroenterol 2016;36:256-60. 
15. Andersen IB, Jørgensen T, Bonnevie O, Grønbæk M, Sørensen TI. Smoking and alcohol intake as risk factors for bleeding and perforated peptic ulcers: a population-based cohort study. Epidemiology 2000;11:434-9.

16. Testini M, Portincasa P, Piccinni G, Lissidini G, Pellegrini F, Greco L. Significant factors associated with fatal outcome in emergency open surgery for perforated peptic ulcer. World J Gastroenterol 2003;9:2338-40.

17. Chan W, Wong W, Khin L, Soo K. Adverse operative risk factors for perforated peptic ulcer. Ann Acad Med Singap 2000;29:164-7.

18. Taş İ, Ülger BV, Önder A, Kapan M, Bozdağ Z. Risk factors influencing morbidity and mortality in perforated peptic ulcer disease. Ulusal Cerr Derg 2015;31:20-5.

19. Arıcı C, Dinçkan A, Erdoğan O, Bozan H, Çolak T. [Peptic ulcer perforation: an analysis of risk factors affect on operative mortality]. Ulusal Travma Acil Cerrahi Derg 2002;8:142-6. [Article in Turkish]

20. Yamamoto K, Takahashi O, Arioka H, Kobayashi D. Evaluation of risk factors for perforated peptic ulcer. BMC Gastroen- terol 2018;18:1-8.

21. Manglik R, Gopal KV. Correlation of serum amylase and peritoneal fluid amylase with, perforated peptic ulcer and its complications. J Evolution Med Dent Sci 2019;8:2897-902.

22. Lemaitre J, Founas WE, Simoens C, Ngongang C, Smets D, da Costa PM. Surgical management of acute perforation of peptic ulcers. A single centre experience. Acta Chir Belg 2005;105:58891.

23. Grassi R, Romano S, Pinto A, Romano L. Gastro-duodenal perforations: conventional plain film, US and CT findings in 166 consecutive patients. Eur J Radiol 2004;50:30-6.

24. Mäkelä JT, Kiviniemi H, Ohtonen P, Laitinen SO. Factors that predict morbidity and mortality in patients with perforated peptic ulcers. Eur J Surg 2002;168:446-51.

25. Imhof M, Epstein S, Ohmann C, Röher H-D. Duration of survival after peptic ulcer perforation. World J Surg 2008;32:40812.

26. Çakır M, Küçükkartallar T, Tekin A. [Changing surgical methods in peptic ulcer perforation]. Selçuk Üniv Tıp Derg 2011;27:160-1. [Article in Turkish] 